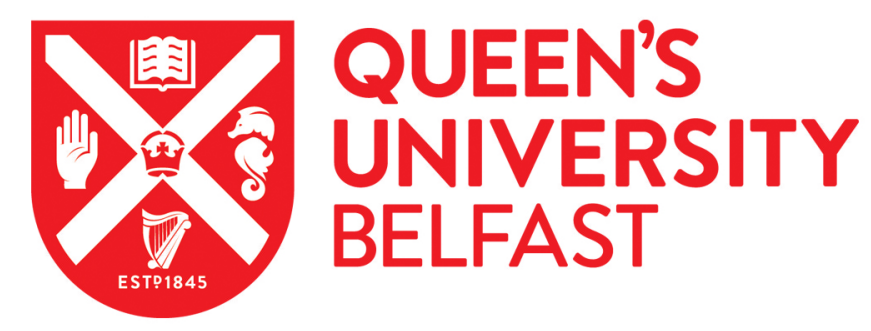

\title{
The Economic Burden of Chronic Diseases: Estimates and Projections for China, Japan, and South Korea
}

Bloom, D. E., Chen, S., Kuhn, M., McGovern, M. E., Oxley, L., \& Prettner, K. (2018). The Economic Burden of Chronic Diseases: Estimates and Projections for China, Japan, and South Korea. The Journal of the Economics of Ageing. https://doi.org/10.1016/j.jeoa.2018.09.002

Published in:

The Journal of the Economics of Ageing

Document Version:

Peer reviewed version

Queen's University Belfast - Research Portal:

Link to publication record in Queen's University Belfast Research Portal

Publisher rights

(c) 2018 Elsevier B. V.

This manuscript version is made available under the CC-BY-NC-ND 4.0 license http://creativecommons.org/licenses/by-nc-nd/4.0/,which permits distribution and reproduction for noncommercial purposes, provided the author and source are cited

\section{General rights}

Copyright for the publications made accessible via the Queen's University Belfast Research Portal is retained by the author(s) and / or other copyright owners and it is a condition of accessing these publications that users recognise and abide by the legal requirements associated with these rights.

Take down policy

The Research Portal is Queen's institutional repository that provides access to Queen's research output. Every effort has been made to ensure that content in the Research Portal does not infringe any person's rights, or applicable UK laws. If you discover content in the Research Portal that you believe breaches copyright or violates any law, please contact openaccess@qub.ac.uk. 
The Economic Burden of Chronic Diseases: Estimates and Projections for China, Japan, and South Korea

David E. Bloom, Simiao Chen, Michael Kuhn, Mark E. McGovern, Les Oxley, and Klaus

Prettner

NBER Working Paper No. 23601

July 2017

JEL No. H51,I15,I18,J24,O11

\section{ABSTRACT}

We propose a novel framework to analyse the macroeconomic impact of noncommunicable diseases. We incorporate measures of disease prevalence into a human capital augmented production function, which enables us to determine the economic costs of chronic health conditions in terms of foregone gross domestic product (GDP). Unlike previously adopted frameworks, this approach allows us to account for i) variations in human capital for workers in different age groups, ii) mortality and morbidity effects of non-communicable diseases, and iii) the treatment costs of diseases. We apply our methodology to China, Japan, and South Korea, and estimate the economic burden of chronic conditions in five domains (cardiovascular diseases, cancer, respiratory diseases, diabetes, and mental health conditions). Overall, total losses associated with these non-communicable diseases over the period 2010-2030 are $\$ 16$ trillion for China (measured in real USD with the base year 2010), \$5.7 trillion for Japan, and $\$ 1.5$ trillion for South Korea. Our results also highlight the limits of cost-effectiveness analysis by identifying some intervention strategies to reduce disease prevalence in China that are cost beneficial and therefore a rational use of resources, though they are not cost-effective as judged by conventional thresholds.

David E. Bloom

Harvard T. H. Chan

School of Public Health

Department of Global Health and Population

665 Huntington Ave.

Building 1, Suite 1202

Boston, MA 02115

and NBER

dbloom@hsph.harvard.edu

Simiao Chen

Harvard T.H. Chan

School of Public Health

665 Huntington Avenue

Boston, Massachusetts

02115-6021

sic104@mail.harvard.edu

Michael Kuhn

Vienna Institute of Demography

Welthandelsplatz 2 / Level 2

A-1020, Vienna

Austria

Michael.Kuhn@oeaw.ac.at
Mark E. McGovern

Queen's University Belfast

Queen's Management School

Riddel Hall

185 Stranmillis Road

BT95EE, Belfast

United Kingdom

m.mcgovern@qub.ac.uk

Les Oxley

Department of Economics

University of Waikato

Hamilton, New Zealand

loxley@waikato.ac.nz

Klaus Prettner

University of Hohenheim

Institute of Economics

Schloss Hohenheim 1d

70593 Stuttgart

Germany

Germany

Klaus.prettner@uni-hohenheim.de 


\section{Introduction}

Globally, non-communicable diseases (NCDs) result in $65 \%$ of all deaths (Lozano et al., 2011) and $54 \%$ of all healthy life years lost as measured by DALYs (disability-adjusted life years) (Murray et al., 2013). Apart from the enormous burden of pain and suffering that these conditions impose, the global economic burden of non-communicable diseases has been estimated to be in the region of $\$ 47$ trillion during 2010 through 2030 (measured in real USD with the base year being 2010, or 75\% of global GDP in 2010; see Bloom et al., 2012). Moreover, the prevalence of chronic conditions, specifically non-communicable diseases such as cardiovascular diseases, cancer, respiratory diseases, diabetes, and mental health conditions, is likely to rise substantially over the coming decades (Kearney et al., 2005).

This phenomenon is likely to affect not only developed countries but also low- and middleincome countries as a result of changes in modifiable risk factors (such as smoking, dietary, and exercise patterns) and non-modifiable risk factors (such as population ageing). One important factor that drives chronic disease prevalence worldwide is changing lifestyle patterns shifting daily living toward more sedentary occupations and less healthy diets. Urbanization has many economic benefits in terms of returns to agglomeration, specialization, and efficiency, but it can also negatively affect population health through mechanisms such as diffusion of risky behaviour and exposure to pollution. For example, an important difference in risk factor trajectories between low- and middle-income countries and highincome countries is the divergence in smoking patterns. While cigarette and tobacco consumption has been falling in many high-income countries, smoking has been rising in India and China. Given that tobacco consumption is the most important risk factor for many non-communicable diseases, this is likely to raise the prevalence of non-communicable diseases in those countries. Another difference between developed and developing countries is that the former have been quite successful at minimising the risk of death associated with communicable diseases, whereas communicable diseases remain a major contributor to mortality in low-income countries. This implies that low-income countries often face a double burden of disease.

In developed countries, population ageing is an inexorable consequence of fertility and mortality patterns. Many high-income countries already face rapid demographic change, and because chronic conditions tend to increase with age, the proportion of their populations affected by non-communicable diseases will rise. Likewise, many emerging economies are either already experiencing population ageing or will do so in the near future. Particularly interesting cases for studying the effects of ageing-related increases in non-communicable disease prevalence are Japan, because it has the largest share of older people globally, and China and South Korea because they are experiencing very rapid population ageing. The 
main goals of this paper are to estimate and project the economic burden of chronic conditions for these three countries until 2030 and to compare the challenges these countries face in terms of non-communicable disease impact.

Through several pathways, disease burden is expected to affect economic outcomes in general and economic growth in particular. First, chronic conditions reduce the supply of labour through mortality, early retirement (Dwyer and Mitchell, 1999; Lindeboom and Kerkhofs, 2009; Jones et al., 2010), and reduced productivity (López-Casasnovas et al., 2005; Jäckle and Himmler, 2010). In addition, individuals may alter their employment behaviour because they anticipate or fear the future onset of illness and negative effects of health conditions (McGarry, 2004). ${ }^{1}$ Second, current interventions related to NCDs (including medical treatment and prevention) require a substantial amount of resources, part of which could otherwise be used for other productive activities. Therefore, NCDs reduce the net availability of government funds and impede the accumulation of physical and human capital by, for example, diverting investment from important areas such as education and infrastructure. Additionally, reduced productivity together with lower labour supply leads to a decline in aggregate income and therefore further reduce savings and investment. Our model addresses these pathways and is summarized in Figure 1.

Overall, the global burden associated with non-communicable diseases can be expected to grow in magnitude. While a substantial literature describes the micro-level effects of health conditions such as cancer on economic and overall well-being, less evidence exists on how chronic conditions interact to affect aggregate outcomes in the population as a whole. The aggregate view is typically absent from studies of the individual-level effects of non-communicable diseases because capturing spillover effects and externalities is difficult where the health status of one person affects the well-being of another individual or group of individuals.

The economic impact of health conditions in general, and non-communicable diseases in particular, is of special importance and interest to policymakers. Faced with increases in the prevalence of chronic conditions, governments and other stakeholders may wish to enact policies that are effective at reducing disease incidence and its consequences. Several possible interventions can reduce the prevalence of non-communicable diseases. For example, a series of "best-buy" investments has been proposed because they are costeffective and easy to implement within the constraints of low- and middle-income countries. These policies include increasing taxes on alcohol and tobacco use, reducing salt intake in food, and replacing trans fats with polyunsaturated fats (Bloom et al., 2011).

However, establishing whether particular programs are worthy of investment can be diffi-

\footnotetext{
${ }^{1}$ For a theoretical analysis of the interrelationship between health and retirement behaviour, see Bloom et al. (2007, 2014d). Building on this, Prettner and Canning (2014) explore the macroeconomic implications, and Kuhn et al. (2015) study the interaction between health and retirement behaviour.
} 
Figure 1: Summary of Pathways from NCDs to Economic Growth

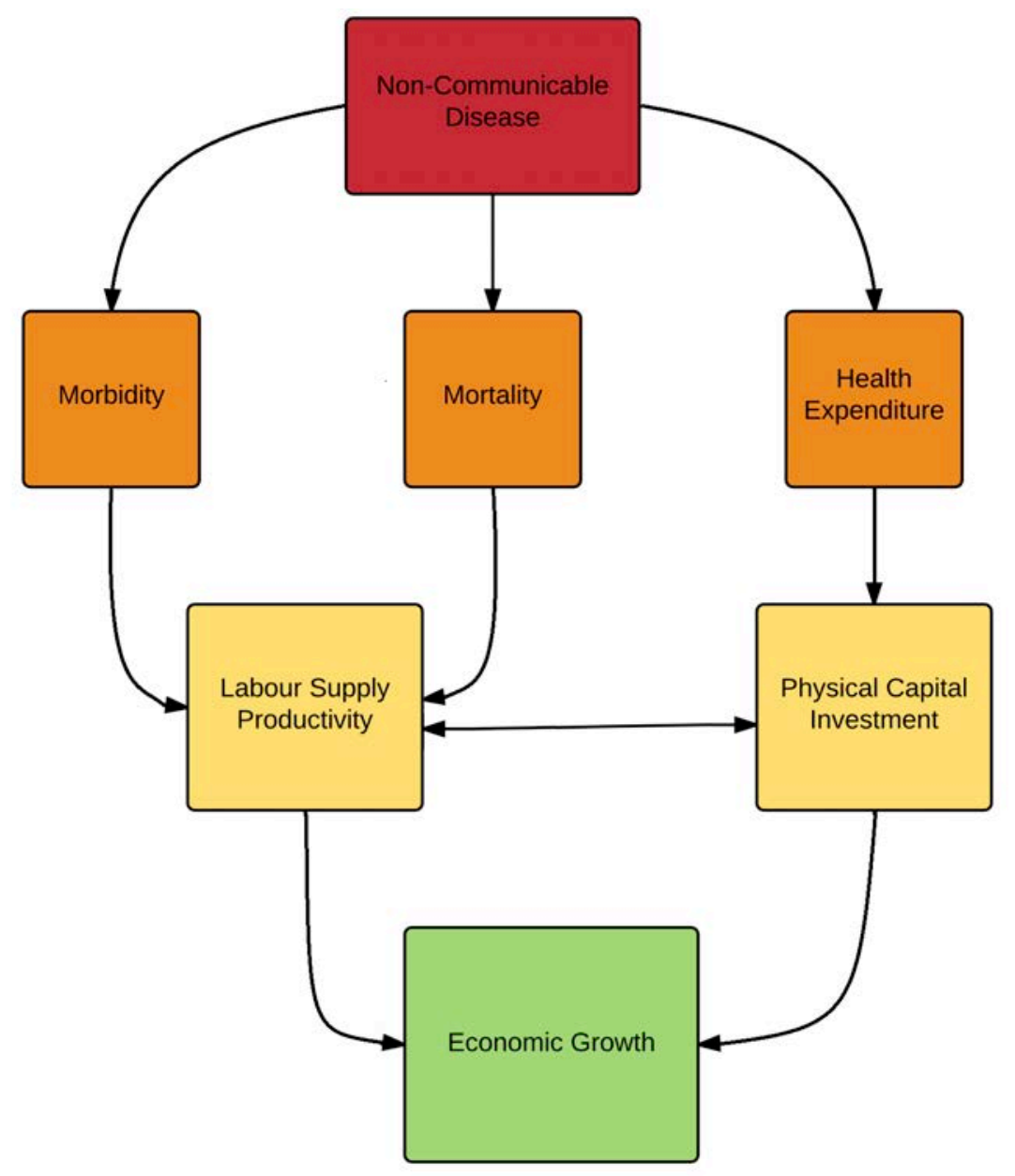

cult without a thorough assessment of the economic benefits of these interventions and a summary of the potential returns on investment for different policy options. This is particularly the case for many candidate policies, not just in the health domain, but also in relation to other sectors such as targeting improvements in infrastructure and education, or when other health conditions such as communicable diseases remain highly prevalent. In addition, policymakers and the public may be unaware of the impact of these conditions, particularly on labour markets and on capital accumulation. A thorough assessment of the economic impact of non-communicable diseases will therefore provide evidence on which types of policies are viable and establish whether investments in health in general, and chronic conditions in particular, are likely to provide returns on investment sufficient to justify their implementation. In sum, accurate estimates of the economic burden of non-communicable diseases are important for providing a cost-benefit analysis of alternative interventions and for ranking alternative policy strategies in terms of their return on investment.

Approaches to estimating the economic effects of health conditions include the cost of 
illness method, where the direct costs associated with a disease are calculated; the value of a statistical life (VSL) approach, where costs are inferred from willingness to pay studies or observed avoidance behaviour for risky occupations or scenarios; econometric estimates taken from cross-country growth regressions; and macroeconomic models (such as a production function-based approach or a general-equilibrium framework), where output trajectories for different scenarios are simulated. Each approach has advantages and disadvantages. In our paper, we aim to account for the aggregate effects on output when estimating the full economic impact of non-communicable diseases. Therefore, we adopt a macroeconomic approach that incorporates disease prevalence into a human capital augmented production function. In this way, we can model the effects of chronic conditions on aggregate effective labour supply and on capital accumulation in a flexible framework that can be used to characterize an extensive set of pathways through which health affects the economy. ${ }^{2}$

Our main contribution is to modify and extend the model that Abegunde and Stanciole (2006) first used to examine the impact of non-communicable diseases on economic growth. The original formulation of the basic approach, which was named the EPIC (or Projecting the Economic Cost of Ill Health) tool, relied on the Solow (1956) framework and was designed by the World Health Organization (WHO). ${ }^{3}$ Altogether, we propose a novel framework that builds upon the WHO EPIC tool, but additionally considers i) heterogeneous human capital levels of workers in different age groups, ii) that NCDs and health conditions not only lead to mortality but also to morbidity, and iii) the effect of treatment costs on capital accumulation.

While our analysis focuses on NCDs, the framework we develop here is quite general and could easily apply to other health domains, such as communicable diseases, road traffic accidents, and tobacco control. We focus on chronic conditions for several reasons. First, the data requirements to implement the model for the four NCDs that are the focus of the United Nations (cardiovascular diseases, cancer, chronic respiratory diseases, and diabetes) and mental health conditions are already quite substantial, and extending the model in this paper to include other health conditions would result in a very lengthy exposition. Second, the countries we consider (China, Japan, and South Korea) are either middle- or highincome countries that have made great strides in dealing with communicable diseases. However, NCDs have been relatively neglected from a public health point of view in these countries, and unlike communicable diseases, the prevalence of chronic conditions is expected to rise substantially over the coming decades. Finally, we are interested in assessing the economic impact of population ageing via changes in the health status of

\footnotetext{
${ }^{2}$ See Kuhn and Prettner (2016) for an analysis of the impact of health care on economic growth and welfare within a Blanchard-Romer style general equilibrium model, in which they take account both of morbidity and mortality related channels.

${ }^{3}$ The basic EPIC model has been used to estimate the economic burden of chronic conditions in India, China, Indonesia, and worldwide (cf. Bloom et al., 2012, 2014a,b, 2015).
} 
the population, and because age is an important non-modifiable risk factor for NCDs, we believe that focusing on these conditions is desirable. Nevertheless, we hope to extend the model to other aspects of health in future research.

The paper is organized as follows. Section 2 compares the four most popular methods used to assess the economic burden of different diseases and discusses their advantages and disadvantages. Section 3 proposes a novel framework that builds upon the WHO EPIC tool but additionally considers heterogeneous human capital levels of workers in different age groups, the morbidity effect of NCDs, and the effect of treatment costs on capital accumulation. Section 4 implements the model for China, Japan, and South Korea and presents the results for these three countries. Section 5 summarizes and draws conclusions.

\section{Comparison of methods to assess the economic burden of diseases}

This section describes the main approaches used to quantify the economic impact of health conditions, focusing on the advantages and disadvantages of each framework. We start with the cost of illness (COI) approach, which is a simple and easy-to-understand method that summarizes the burden of a certain disease over a particular time period in a single number. This number is defined as the sum of all personal medical care costs (e.g., inpatient and outpatient hospital costs); personal non-medical care costs (e.g., transportation and relocation expenses); non-personal costs (e.g., for research activities); and loss of income due to absenteeism, early retirement, or premature death. Altogether, the medical costs, the non-medical costs, and the research costs are referred to as direct costs, while the loss of income is referred to as an indirect cost. ${ }^{4}$ The advantage of this method is that the outcome is easily interpreted as the monetary value of the resources that could be saved by avoiding a particular disease. The main drawbacks are that no economic adjustment mechanisms are considered (e.g., the substitution of labour lost due to an illness by capital or other workers) and that COI studies disregard the effect of diseases on physical capital and human capital accumulation (for a general debate on the usefulness of the COI approach see Currie et al., 2000; Rice, 2000; World Health Organization, 2009).

An alternative way to estimate the costs of health conditions is to reconstruct a person's implicit valuation of his/her own life, the value of a statistical life, by estimating a person's willingness to accept premia for risky occupations via wage regressions, or by estimating a person's willingness to pay for the reduction of risks via hedonic price regressions (Viscusi and Aldy, 2003). The monetary value that a person assigns to his/her own life can be inferred from the parameter estimates in these regressions. The main advantage of this

\footnotetext{
${ }^{4}$ Most studies of the costs of NCDs rely on this approach (as an example, see Beaulieu et al., 2009).
} 
approach is that it also delivers a single number that, if multiplied by the number of cases, can be interpreted as the total statistical value of the loss due to an illness. While the COI approach focuses more on the objective costs of an illness, the VSL approach also implicitly covers the costs of pain and suffering via the revealed preferences of the consumers/workers who are studied. Prominent studies by Murphy and Topel (2006) and Lakdawalla et al. (2010) apply the VSL methodology to calculate the value of advances against cardiac disease and cancer. The main drawback is that the VSL approach yields an estimate of the statistical loss due to an illness that strongly depends on the age and the income level of workers. Consequently, the estimates vary widely among different countries. Furthermore, economic adjustment mechanisms are again not taken into consideration. ${ }^{5}$

Another method to assess the economic costs of an illness is to estimate a cross-country growth regression in the vein of Barro (1991) and Islam (1995), in which the main regressors of interest contain the prevalence of the illness under consideration. From the parameter estimate associated with the prevalence of an illness, its impact on growth can be inferred directly (see Suhrcke and Urban, 2010, for estimates of the negative growth effect of cardiovascular diseases). The advantage of this approach is that, when the regression is appropriately specified, the estimated growth effect is readily apparent from the final result, which already incorporates economic adjustment mechanisms. Consequently, this method overcomes one of the crucial shortcomings of the COI and VSL approaches. However, growth regressions are very data intensive, requiring a wide range of precisely measured control variables for all countries in the sample (see Durlauf et al., 2005; Eberhardt and Teal, 2011; Sala-i Martin et al., 2004; Sala-i Martin, 1997, for discussions). Furthermore, the result is an average of the growth effect over all countries included in the regression, which does not account for specific country characteristics and potential heterogeneity in the impact of chronic conditions across countries. Additionally, this approach only allows for an assessment of severe diseases that affect many people (such as cardiovascular diseases). Detecting a significant growth effect for less severe diseases that do not affect many people is difficult given the small sample sizes that typically confront growth regressions (cf. Durlauf et al., 2005). Finally, attempts to deal with reverse causality and omitted variable bias are contentious in the literature (Weil, 2014).

Abegunde and Stanciole (2006) and the WHO first proposed the EPIC framework, which simulates a Solow (1956) growth model that considers the adverse effects of diseases on physical capital accumulation and on labour supply. Bloom et al. (2012, 2014a,b, 2015) have applied this framework to several developed and less developed countries. While the EPIC approach accounts for the fact that physical capital or other workers can replace lost labour and therefore allows for economic adjustment mechanisms, it only considers mortality and not morbidity. Furthermore, it does not accurately account for the cost of

\footnotetext{
${ }^{5}$ See Frankovic et al. (2016) for a theoretical analysis of how the VSL responds to exogenous medical progress in general equilibrium.
} 
treatments and for the fact that different age groups of workers have, in general, different productivity levels because of their different schooling intensity and experience patterns. This is, however, important because of the relative concentration of chronic conditions among older age groups.

Our contribution focuses on these three shortcomings of the EPIC model and proposes a novel framework that builds upon the Lucas (1988) production function. In so doing, we explicitly allow different age groups of workers to have different education levels and different levels of experience, and we address the lack of a morbidity mechanism by incorporating information on disease morbidity, as measured by DALYs reported by the Institute for Health Metrics and Evaluation (2013). Furthermore, we account for the treatment costs of diseases.

The production function-based framework we use also has some limitations. First, it is not a general equilibrium model in the sense that all decisions are microfounded. For example, individuals who live longer because the prevalence of a disease is reduced might invest more in education or they might save more. While implementing a general equilibrium structure would be highly complex and would require other restrictive assumptions to be tractable, disregarding the mentioned general equilibrium repercussions implies that our estimates of the economic burden of NCDs are conservative. Another issue with the production function-based framework is that we consider the impact of health on growth, but do not model a channel linking growth to health. ${ }^{6}$ Incorporating a channel reflecting an effect of economic growth on health would be arbitrary in the absence of good evidence on the causal pathways of interest and would introduce additional complexity into the model. Nevertheless, abstracting from a feedback effect of economic growth on health clearly implies that the economic burden of NCDs that we calculate is likely to be a lower bound for the true costs.

\section{The model}

We aim to quantify the economic burden of a particular disease, which requires us to compare economic performance between two scenarios: a status quo scenario, in which GDP is projected to grow based on current estimates and projections of disease prevalence, and a counterfactual scenario, in which the disease prevalence is eliminated from the beginning of the time period. We define the overall economic impact of the relevant

\footnotetext{
${ }^{6}$ The nature of the relationship between health and growth and the potential for reverse causality has been debated extensively in both the macroeconomics and microeconomics literature (see, for example, Acemoglu and Johnson, 2007, 2014; Aghion et al., 2011; Bloom et al., 2004, 2014c; Cervellati and Sunde, 2011; Cutler et al., 2006; Pritchett and Summers, 1996; Weil, 2007, 2014). While health and income are typically highly correlated, the precise nature of the relationship remains controversial because of the difficulties associated with identifying the causal effects of interest.
} 
disease as the cumulative difference between status quo GDP and counterfactual GDP in each year (summed over the time period of interest). This framework is very flexible and allows us to examine alternative scenarios in which GDP is calculated for a designated percentage reduction in the prevalence of a specific disease. This allows us to analyse the impact of a particular policy intervention, with the cost of the intervention factored into a corresponding decrease in capital accumulation.

\subsection{Human capital, physical capital, and aggregate output}

Consider an economy populated by individuals of different age $a$ in which time $t \in[0, \infty]$ evolves discretely. Individuals of age group $a$ are endowed with $h_{t}^{(a)}$ units of human capital and supply $\ell_{t}^{(a)}$ units of labour from age 15 up to their retirement at age $R$, i.e., for $a \in[15, R]$. Children below the age of 15 and retirees above the age of $R$ do not work. At the aggregate level are two production factors: physical capital $\left(K_{t}\right)$ and human capital $\left(H_{t}\right)$. Human capital is defined as the aggregate age-specific effective labour supply

$$
H_{t}=\sum_{a=15}^{R} h_{t}^{(a)} \ell_{t}^{(a)} N_{t}^{(a)},
$$

where $N_{t}^{(a)}$ denotes the number of individuals belonging to age group $a$. Note that aggregate human capital is greater if more individuals of working age live in the economy (i.e., $N_{t}=\sum_{a=15}^{R} N_{t}^{(a)}$ is larger), if those individuals are endowed with more human capital because they are either better educated or have more experience (i.e., $h_{t}^{(a)}$ is higher for at least one $a$ ), and if individuals in the economy supply more labour (i.e., $\ell_{t}^{(a)}$ is higher for at least one $a$ ).

Aggregate output $Y_{t}$ is used for three purposes: to pay treatment costs $T C_{j, t}{ }^{7}$ for disease $j \in \mathcal{I}$, where $\mathcal{I}$ is the set of diseases; to consume the quantity $C_{t}$; and to save. As a consequence, physical capital $(K)$ accumulates according to

$$
K_{t+1}=(1-\delta) K_{t}+Y_{t}-C_{t}-\sum_{j \in \mathcal{I}} T C_{j, t}=(1-\delta) K_{t}+s_{t} Y_{t}
$$

where $\delta$ is the rate of depreciation and $s_{t}$ refers to the savings rate. From Equation (2) it follows that the savings rate is defined as

$$
s_{t}=1-\frac{C_{t}+\sum_{j \in \mathcal{I}} T C_{j, t}}{Y_{t}}
$$

\footnotetext{
${ }^{7}$ These costs refer to the costs of ongoing treatment and of the intervention methods for the specific disease. In general, these costs are best characterized by the direct costs of healthcare including hospitalization, medication, etc.
} 
Building upon Lucas (1988), aggregate output is given by the production function

$$
Y_{t}=A_{t} K_{t}^{\alpha}\left(\sum_{a=15}^{R} h_{t}^{(a)} \ell_{t}^{(a)} N_{t}^{(a)}\right)^{1-\alpha},
$$

where $A_{t}$ is the technological level of the economy that evolves exogenously and $\alpha$ is the elasticity of final output with respect to physical capital. The aggregate production function takes into account that output is not only produced with physical capital and raw labour as in the Solow (1956) framework on which the original EPIC model relies, but with effective labour of which human capital is a central determinant.

We follow Mincer (1974) and construct average human capital of the cohort aged $a$ according to an exponential function of education and work experience:

$$
h_{t}^{(a)}=\exp \left[\eta_{1}\left(y s_{t, p r i m}^{(a)}\right)+\eta_{2}\left(y s_{t, \text { sec }}^{(a)}\right)+\eta_{3}\left(y s_{t, \text { tert }}^{(a)}\right)+\eta_{4}(a-15)-\eta_{5}(a-15)^{2}\right],
$$

where $\eta_{1}$ is the semi-elasticity of human capital with respect to years of primary education as given by $y s_{t, p r i m}^{(a)}, \eta_{2}$ is the semi-elasticity of human capital with respect to years of secondary education as given by $y s_{t, s e c}^{(a)}, \eta_{3}$ is the semi-elasticity of human capital with respect to years of tertiary education as given by $y s_{t, t e r t}^{(a)}$, and $\eta_{4}$ and $\eta_{5}$ are the semielasticities of human capital with respect to the experience of the workforce $(a-15)$ and the experience of the workforce squared $(a-15)^{2}$, respectively. The values for the parameters $\eta_{1}, \eta_{2}$, and $\eta_{3}$ are taken from the studies by Hall and Jones (1999) and Psacharopoulos (1994), while the values for $\eta_{4}$ and $\eta_{5}$ are taken from Heckman et al. (2006). ${ }^{8}$

Non-communicable diseases exert influence on the economy via three pathways: i) via physical capital accumulation in the sense that savings finance part of the treatment costs, reducing physical capital accumulation; ii) via effective labour supply in two ways: first, disease-induced mortality reduces the population and hence the number of workers, and second, the associated morbidity reduces individual productivity and increases absenteeism; and via the average human capital level because NCDs disproportionately affect more experienced age groups.

\subsection{Impact on physical capital accumulation}

In the counterfactual scenario, we assume that a certain disease $i \in \mathcal{I}$ is eliminated, so the treatment costs for disease $i$ in Equation (2) are set to zero. Moreover, we define $I C_{i, t}$ to be the cost for the intervention that helps eliminate this disease, whereas $T C_{i, t}$ refers to

\footnotetext{
${ }^{8}$ Note that another pathway exists, whereby a bad health condition affects human capital that we do not account for by our specification: absenteeism due to bad health might lead to faster depreciation of human capital because it sits idle.
} 
the treatment costs that would have been incurred without the elimination of the disease. The accumulation of physical capital can then be written as

$$
\bar{K}_{t+1}=\bar{Y}_{t}-\bar{C}_{t}+(1-\delta) \bar{K}_{t}-\sum_{j \in \mathcal{I}, j \neq i} T C_{j, t}-I C_{i, t}
$$

where an overbar indicates that the corresponding variable refers to the counterfactual scenario. Because the disease is assumed to be eliminated with a cost $I C_{i, t}$, the resources that were devoted to its treatment can now be used for savings or for consumption. Notice that this creates an income effect that, in reality, could affect the division of households' income between savings, and consumption. For tractability, we assume that, in the counterfactual scenario, aggregate investment consists of two parts: a fixed share $s_{t}$ of total output and an additional part from $\left(T C_{i, t}-I C_{i, t}\right)$ that would otherwise have been used to pay for the treatment of disease $i$ (after netting out the intervention cost):

$$
\bar{I}_{t}=\bar{Y}_{t}-\bar{C}_{t}-\sum_{j \in \mathcal{I}, j \neq i} T C_{j, t}=s_{t} \bar{Y}_{t}+\chi\left(T C_{i, t}-I C_{i, t}\right)
$$

In this expression, $\chi$ is the fraction of the treatment cost that is diverted to savings and we have the counterfactual savings rate

$$
\bar{s}_{t}=\frac{s_{t} \bar{Y}_{t}+\chi\left(T C_{i, t}-I C_{i, t}\right)}{\bar{Y}_{t}} .
$$

As a result, the savings rate could increase if the treatment cost outweighed the intervention cost.

\subsection{Impact on labour supply}

The evolution of labour supply in the status quo scenario is given by

$$
L_{t}^{(a)}=N_{t}^{(a)} \ell_{t}^{(a)} \quad \text { with } \quad N_{t}^{(a)}=\left[1-\sigma_{t-1}^{(a-1)}\right] N_{t-1}^{(a-1)},
$$

where $\sigma_{t}^{(a)}$ is the overall mortality rate of age group $a$. Denote the mortality rate of people in age group $a$ due to the disease $i$ by $\sigma_{i, t}^{(a)}$ and let $\sigma_{-i, t}^{(a)}$ be the overall mortality rate due to causes other than disease $i$. Then we simply have

$$
\left(1-\sigma_{t}^{(a)}\right)=\left(1-\sigma_{i, t}^{(a)}\right)\left(1-\sigma_{-i, t}^{(a)}\right) .
$$

Now we consider the mortality effect of disease $i$. In general, it reduces labour supply by reducing the population $N_{t}^{(a)}$ (through $\sigma_{i, t}^{(a)}$ ). In the counterfactual case, where the disease is eliminated from time $t=0$ onward, the evolution of labour supply is defined similarly to Equation (7), but with a different overall mortality rate $\left(\sigma_{-i, t}^{(a)}\right.$ instead of $\left.\sigma_{t}^{(a)}\right)$. For 
simplicity, we assume that the number of births is the same in both cases at each point in time $t$. In general, this is a good approximation because most NCDs affect older adults who contribute little to overall fertility.

In the counterfactual scenario, the size of the cohort aged $a$ at time $t\left(\bar{N}_{t}^{(a)}\right)$ evolves according to

$$
\bar{N}_{t}^{(a)}=\left[1-\sigma_{-i, t-1}^{(a-1)}\right] \bar{N}_{t-1}^{(a-1)}, \quad \bar{N}_{0}^{(a)}=N_{0}^{(a)}, \quad \bar{N}_{t}^{(0)}=N_{t}^{(0)} .
$$

More specifically, if $a>t$, then this cohort was born before the elimination of disease $i$ such that

$$
\begin{aligned}
\bar{N}_{t}^{(a)} & =\left[1-\sigma_{-i, t-1}^{(a-1)}\right]\left[1-\sigma_{-i, t-2}^{(a-2)}\right] \bar{N}_{t-2}^{(a-2)} \ldots \\
& =\prod_{\tau=0}^{t-1}\left[1-\sigma_{-i, t-1-\tau}^{(a-1-\tau)}\right] \bar{N}_{0}^{(a-t)}=\prod_{\tau=0}^{t-1}\left[1-\sigma_{-i, t-1-\tau}^{(a-1-\tau)}\right] N_{0}^{(a-t)} .
\end{aligned}
$$

Notice that

$$
N_{t}^{(a)}=\prod_{\tau=0}^{(t-1)}\left[1-\sigma_{t-1-\tau}^{(a-1-\tau)}\right] N_{0}^{(a-t)} .
$$

Hence, we have

$$
\bar{N}_{t}^{(a)}=N_{t}^{(a)} / \prod_{\tau=0}^{(t-1)}\left[1-\sigma_{i, t-1-\tau}^{(a-1-\tau)}\right] .
$$

If $a \leq t$, then this cohort was born after the elimination of disease $i$ such that

$$
\begin{aligned}
\bar{N}_{t}^{(a)} & =\left[1-\sigma_{-i, t-1}^{(a-1)}\right]\left[1-\sigma_{-i, t-2}^{(a-2)}\right] \bar{N}_{t-2}^{(a-2)} \cdots \\
& =\prod_{\tau=0}^{a-1}\left[1-\sigma_{-i, t-1-\tau}^{(a-1-\tau)}\right] \bar{N}_{t-a}^{(0)}=\prod_{\tau=0}^{a-1}\left[1-\sigma_{-i, t-1-\tau}^{(a-1-\tau)}\right] N_{t-a}^{(0)} .
\end{aligned}
$$

Notice that

$$
N_{t}^{(a)}=\prod_{\tau=0}^{(a-1)}\left[1-\sigma_{t-1-\tau}^{(a-1-\tau)}\right] N_{t-a}^{(0)} .
$$

Hence, we have

$$
\bar{N}_{t}^{(a)}=N_{t}^{(a)} / \prod_{\tau=0}^{(a-1)}\left[1-\sigma_{i, t-1-\tau}^{(a-1-\tau)}\right] .
$$

In sum, we arrive at the following equation:

$$
\bar{N}_{t}^{(a)}=N_{t}^{(a)} / \prod_{\tau=0}^{\min \{t, a\}-1}\left[1-\sigma_{i, t-1-\tau}^{(a-1-\tau)}\right],
$$

which accounts for the fact that the loss of labour due to mortality accumulates over the years. 
The morbidity effect of the disease does not change the population size, but can affect the labour participation rate because people with an illness typically reduce their labour supply either by reducing working hours or by leaving the work force. Unlike the mortality effect, tracing the accumulation of morbidity effects over time is complicated because people affected by morbidity can be cured and hence increase their labour supply again in later time periods. To capture this fact, we assume that, in each year, an ill person has a probability $\left(1-p_{i}\right)$ of recovering from the disease. We assume that this probability stays constant over time and that it is independent of the number of years the person lived with the disease. The value of $p_{i}$ can then be easily inferred as the average duration of the disease through

$$
p_{i}=1-\frac{1}{\text { duration of the disease }} .
$$

Because the impact of morbidity is hard to estimate directly, we first define

$$
\xi_{i}^{(a)}=\frac{\text { loss of labour due to morbidity in age group } a}{\text { loss of labour due to mortality in age group } a} .
$$

Next, we assume that the following holds in any given year for age group $a$ :

$$
\xi_{i}^{(a)}=\frac{Y L D_{i}^{(a)}}{Y L L_{i}^{(a)}},
$$

where $Y L D_{i}^{(a)}$ represents the years lived with disease $i$ and $Y L L_{i}^{(a)}$ represents the years of life lost due to disease $i$. Notice that $\xi_{i}^{(a)}$ can be calculated from the corresponding DALY data reported by the Institute for Health Metrics and Evaluation (2013).

Now consider a cohort aged $a$ at time $t$, and let $m_{i}^{(a)}$ be the rate of people leaving the labour force due to morbidity of disease $i$. Then, if (10) is fulfilled, it is easy to see that

$$
m_{i}^{(a)}=\xi_{i}^{(a)} \sigma_{i, t}^{(a)}
$$

Unlike labour supply, which can be derived recursively according to Equation (7), the evolution of the labour participation rate is more complicated. People of different ages have different labour participation rates, so a recursive framework cannot be adopted. For tractability, we assume that the labour participation rate for people who are not affected by disease $i$ is exogenously given. Specifically, we define $\hat{\ell}_{t}^{(a)}$ to be the labour participation rate of people without the disease. Because the morbidity effect drives workers out of the labour force, the status quo labour participation rate is expected to be smaller than $\hat{\ell}_{t}^{(a)}$. Notice that the difference comes from two sources: newly affected people who leave the labour force and people who left the labour force due to disease $i$ years ago and have not yet recovered. To fix the distortion caused by discretisation, we assume that i) at the beginning of year $t$, the labour force $\ell_{t}^{(a)}$ is calculated, and ii) at the end of each year, 
morbidity effects are factored into the population.

Now we restrict our attention to the cohort aged $a$ at time $t$. Notice that $\ell_{t}^{(a)}$ is determined by i) the labour participation rate of "healthy" people $\left(\hat{\ell}_{t}^{(a)}\right)$ and ii) the fraction of "healthy" people at the beginning of year $t\left(F^{(a)}\right)$. Here, "healthy" means that the person has not left the workforce due to morbidity, while the labour participation rate of the "unhealthy" simply equals zero.

Proposition 1. For the cohort aged $\boldsymbol{a}$ at time $\boldsymbol{t}$, the fraction of "healthy" people at the beginning of year $\boldsymbol{t}$ can be approximated by

$$
F^{(a)} \approx \prod_{\tau=0}^{a-1}\left[1-p_{i}^{\tau} m_{i}^{(a-1-\tau)}\right] .
$$

Proof. The case for $a=1$ is trivial. We therefore prove the proposition by induction. Suppose that

$$
F^{(n)} \approx \prod_{\tau=0}^{n-1}\left[1-p_{i}^{\tau} m_{i}^{(n-1-\tau)}\right] .
$$

Then consider age $n+1$, where, with probability $p$, those who are sick at the beginning of age $n,\left(1-F^{(n)}\right)$, will still be sick, whereas the others return to the labour force. Then, the disease will again claim a fraction $m_{i}^{(n)}$ of the total "healthy" population each year. Given that $m_{i}^{(n)}$ for $n=1, \ldots$ is small, we have

$$
\begin{aligned}
F^{(n+1)} & =\left[1-p\left(1-F^{(n)}\right)\right]\left(1-m_{i}^{(n)}\right) \\
& \approx\left(1-p\left\{1-\prod_{\tau=0}^{n-1}\left[1-p_{i}^{\tau} m_{i}^{(n-1-\tau)}\right]\right\}\right)\left(1-m_{i}^{(n)}\right) \\
& \approx \prod_{\tau=0}^{n}\left(1-p_{i}^{\tau} m_{i}^{(n-\tau)}\right) .
\end{aligned}
$$

In this case, we assume that morbidity only affects the proportion of people in the labour force and that it is completely independent of the mortality process.

Now we can write the approximate relationship between $\ell_{t}^{(a)}$ and $\hat{\ell}_{t}^{(a)}$ as

$$
\ell_{t}^{(a)} \approx \hat{\ell}_{t}^{(a)} F^{(a)}=\hat{\ell}_{t}^{(a)} \prod_{\tau=0}^{a-1}\left[1-p_{i}^{\tau} m_{i}^{(a-1-\tau)}\right] .
$$

Although the closed-form solution can be obtained using induction, we prefer to use this approximation for two reasons: first, the complexity is greatly reduced without sacrificing much in the way of accuracy, and second, this approximation provides a very intuitive interpretation and is directly comparable to Equation (8). 
The next step is to generate the labour participation rate of the counterfactual case $\left(\bar{\ell}_{t}^{(a)}\right)$ from that of the status quo case $\left(\ell_{t}^{(a)}\right)$. Notice that here $\bar{\ell}_{t}^{(a)}$ is different from $\hat{\ell}_{t}^{(a)}$. The former represents the labour participation rate of the counterfactual case in which the disease is eliminated from $t=0$ onward; the latter is the labour participation rate of "healthy" people. If $a \leq t$, the cohort was born after the elimination of disease $i$ and hence we have $\bar{\ell}_{t}^{(a)}=\hat{\ell}_{t}^{(a)}$ (everyone is "healthy" in this cohort). If $a>t$, then the cohort was born before the elimination of the disease. In this case, some members of the cohort may have contracted the disease before $t=0$ and not recovered yet. Knowing this, we have the following:

$$
\begin{gathered}
\bar{\ell}_{t}^{(a)}=\hat{\ell}_{t}^{(a)}, \quad t \geq a, \\
\bar{\ell}_{t}^{(a)} \approx \hat{\ell}_{t}^{(a)} \prod_{\tau=t}^{a-1}\left[1-p_{i}^{\tau} m_{i}^{(a-1-\tau)}\right], \quad t<a .
\end{gathered}
$$

Combining (12), (13), and (14), we get

$$
\bar{\ell}_{t}^{(a)} \approx \ell_{t}^{(a)} / \prod_{\tau=0}^{\min \{t, a\}-1}\left[1-p_{i}^{\tau} m_{i}^{(a-1-\tau)}\right]=\ell_{t}^{(a)} / \prod_{\tau=0}^{\min \{t, a\}-1}\left[1-p_{i}^{\tau} \sigma_{i, t-1-\tau}^{(a-1-\tau)} \xi_{i}^{(a-1-\tau)}\right] .
$$

From Equation (15), we see that a larger $p_{i}$ leads to a lower participation rate, i.e., the morbidity effect is more likely to accumulate over the years if the disease is hard to cure. The intuition behind Equation (15) is the following: the different exposure to the disease drives the difference between the labour participation rate of the status quo $\left(\ell_{t}^{(a)}\right)$ and the counterfactual case $\left(\bar{\ell}_{t}^{(a)}\right)$. For $a \leq t$, the cohort in the counterfactual case avoided exposure to the disease completely in the previous $a$ years. For $a>t$, the cohort only avoided exposure to the disease in the most recent $t$ years.

Overall, the loss of labour supply in age group $a$ at time $t$ can be calculated as

$$
\begin{aligned}
\Delta L_{t}^{(a)} & =\bar{L}_{t}^{(a)}-L_{t}^{(a)}=\ell_{t}^{(a)} N_{t}^{(a)}\left\{\frac{1}{\prod_{\tau=0}^{\min \{t, a\}-1}\left[1-p_{i}^{\tau} m_{i}^{(a-1-\tau)}\right]\left[1-\sigma_{i, t-1-\tau}^{(a-1-\tau)}\right]}-1\right\} \\
& \approx \ell_{t}^{(a)} N_{t}^{(a)} \sum_{\tau=0}^{\min \{t, a\}-1} \sigma_{i, t-1-\tau}^{(a-1-\tau)}\left[1+p_{i}^{\tau} \xi_{i}^{(a-1-\tau)}\right] .
\end{aligned}
$$

The approximation in Equation (16) results from the observation that $\sigma_{i, t}^{(a)}$ and $\xi_{i}^{(a)}$ are typically small numbers. Defining the term in curly brackets as $M_{i, t}^{(a)}$ it follows that

$$
\Delta L_{t}^{(a)}=L_{t}^{(a)} M_{i, t}^{(a)}
$$

Intuitively, $M_{i, t}^{(a)}$ can be interpreted as the cumulative labour supply impact of disease $i$ on the cohort aged $a$ at time $t$. 
By plugging (17) into (1), the loss of human capital due to disease $i$ at time $t$ can be written in percentage terms as

$$
\frac{\Delta H_{t}}{H_{t}}=\frac{\sum_{a=15}^{R} h_{t}^{(a)} \ell_{t}^{(a)} N_{t}^{(a)} M_{i, t}^{(a)}}{\sum_{a=15}^{R} h_{t}^{(a)} \ell_{t}^{(a)} N_{t}^{(a)}} .
$$

Equation (18) implies that the human capital loss is related to the country's demographic structure. Even if the mortality and morbidity effects of a disease were similar in two countries for each age group ( $\operatorname{similar} M_{i, t}^{(a)}$ for both countries), the aggregate human capital loss could still vary vastly due to the different weights $\left(h_{t}^{(a)} \ell_{t}^{(a)} N_{t}^{(a)}\right)$ on each age group.

Now, instead of completely eliminating the disease, suppose that the intervention only reduces the disease prevalence by a certain percentage, say $\rho$. The previous discussion still holds true, and we can obtain the loss of labour by replacing $\left(\sigma_{i, t}, m_{i, t}\right)$ with $\left(\rho \sigma_{i, t}, \rho m_{i, t}\right)$ in (16). Denoting the loss of labour for age group $a$ at time $t$ in case of a reduction in the disease prevalence by $\rho$ as $\Delta L_{t}^{(a)}(\rho)$, it is easy to show that

$$
\begin{aligned}
\Delta L_{t}^{(a)}(\rho) & \approx \ell_{t}^{(a)} N_{t}^{(a)} \sum_{\tau=0}^{\min \{t, a\}-1} \rho \sigma_{i, t-1-\tau}^{(a-1-\tau)}\left[1+p_{i}^{\tau} \xi_{i}^{(a-1-\tau)}\right] \\
& \approx \rho L_{t}^{(a)} M_{i, t}^{(a)}
\end{aligned}
$$

where $M_{i, t}^{(a)}$ is defined in (17), and the approximation is valid when $\sigma_{i, t}$ and $m_{i, t}$ are small. Equation (19) shows that the cumulative loss of labour is approximately linear with respect to disease prevalence averted $(\rho)$ given that the mortality and morbidity of the disease are small.

Our approach has the following advantages over the standard EPIC tool: first, we can account for morbidity by adjusting the labour participation rate by disease based on the data of the Institute for Health Metrics and Evaluation (2013); second, we can infer the impact of a disease on physical capital accumulation by obtaining $\chi$ and $T C_{i, t}$ directly from the data; and third, human capital accumulation is considered by employing a Mincerian specification that allows for distinctions among primary, secondary, and tertiary education and allows for the consideration of experience.

\section{Results}

We present direct estimates for five conditions for which the necessary mortality data are available in EPIC (ischemic heart disease, cerebrovascular disease, diabetes, chronic obstructive pulmonary disease (COPD), and breast cancer). The results are then scaled up using Institute for Health Metrics and Evaluation (2013) data on DALYs to reflect 
the four NCDs that are the focus of the United Nations (cardiovascular diseases, cancer, chronic respiratory diseases, and diabetes), plus mental health conditions. The scaling is implemented by calculating the proportion of DALYs in a particular domain (e.g., cancer) that the relevant disease accounts for in EPIC (breast cancer in this instance). If breast cancer accounts for $10 \%$ of the total DALYs lost to cancer, the scaling factor applied to our results for breast cancer to obtain a result for all cancers is 0.1. Scaling factors are calculated for each country. Similarly, we use WHO data on mental illness DALYs to include estimates of economic losses from mental health conditions. The mental health scaling factor is calculated by obtaining the ratio of DALYs accounted for by the four NCD domains to the DALYs accounted for by mental health conditions. Obtaining comprehensive information on the treatment costs associated with each disease is difficult. As Table A1 shows, we calculated treatment costs from various sources. For the missing data, we adjusted for cross-country differences using data on health expenditures per capita from the World Bank database and adjusted to account for inflation. In addition, for each country we assumed a fixed annual growth rate of the per capita treatment costs to adjust for rising medical costs. The annual growth rate of the per capita health expenditure from 2005 to 2014 approximates this number, which is $13.4 \%$ for China, $4.6 \%$ for Japan, and $7.8 \%$ for South Korea. The treatment cost estimates in 2010 are listed in Table A2 in the Appendix. The GDP projections for the status quo scenario are taken from the World Bank's Global Economic Prospects (2017).

Table 1 describes other data sources, while we show disease-specific estimates (ischemic heart disease, cerebrovascular disease, diabetes, chronic obstructive pulmonary disease, and breast cancer, before scaling) for each $\%$ of disease prevalence averted for each country in Figure 2 (China), Figure 3 (Japan), and Figure 4 (South Korea). Table 2 shows diseasespecific burden as well as scaled estimates of the total disease burden ( $100 \%$ of mortality averted for cardiovascular diseases, cancer, chronic respiratory diseases, diabetes, and mental health conditions) for the period 2010-2030.

Table 1: Parameter Values and Data Sources

\begin{tabular}{lrr}
\hline Parameter & Value & Source \\
\hline$\alpha$ & $1 / 3$ & e.g., Jones (1995) \\
$\delta$ & $0.04-0.05$ & e.g., Grossmann et al. (2013) \\
$s$ & World Bank (2015) \\
$\eta_{1}$ & Depends on the country & Psacharopoulos (1994), Hall and Jones (1999) \\
$\eta_{2}$ & 0.134 & Psacharopoulos (1994), Hall and Jones (1999) \\
$\eta_{3}$ & 0.068 & Psacharopoulos (1994), Hall and Jones (1999) \\
$\eta_{4}$ & $0.09-0.132$ & Heckman et al. (2006) \\
$\eta_{5}$ & -0.0023 to -0.0013 & Heckman et al. (2006) \\
$\xi_{i}$ & Depends on the country & Institute for Health Metrics and Evaluation (2013) \\
$\chi_{i}$ & Depends on the country & Calculated through other parameters \\
\hline
\end{tabular}


Figure 2: Differential GDP Associated with Averted Disease Prevalence for China (in billions of 2010 USD)

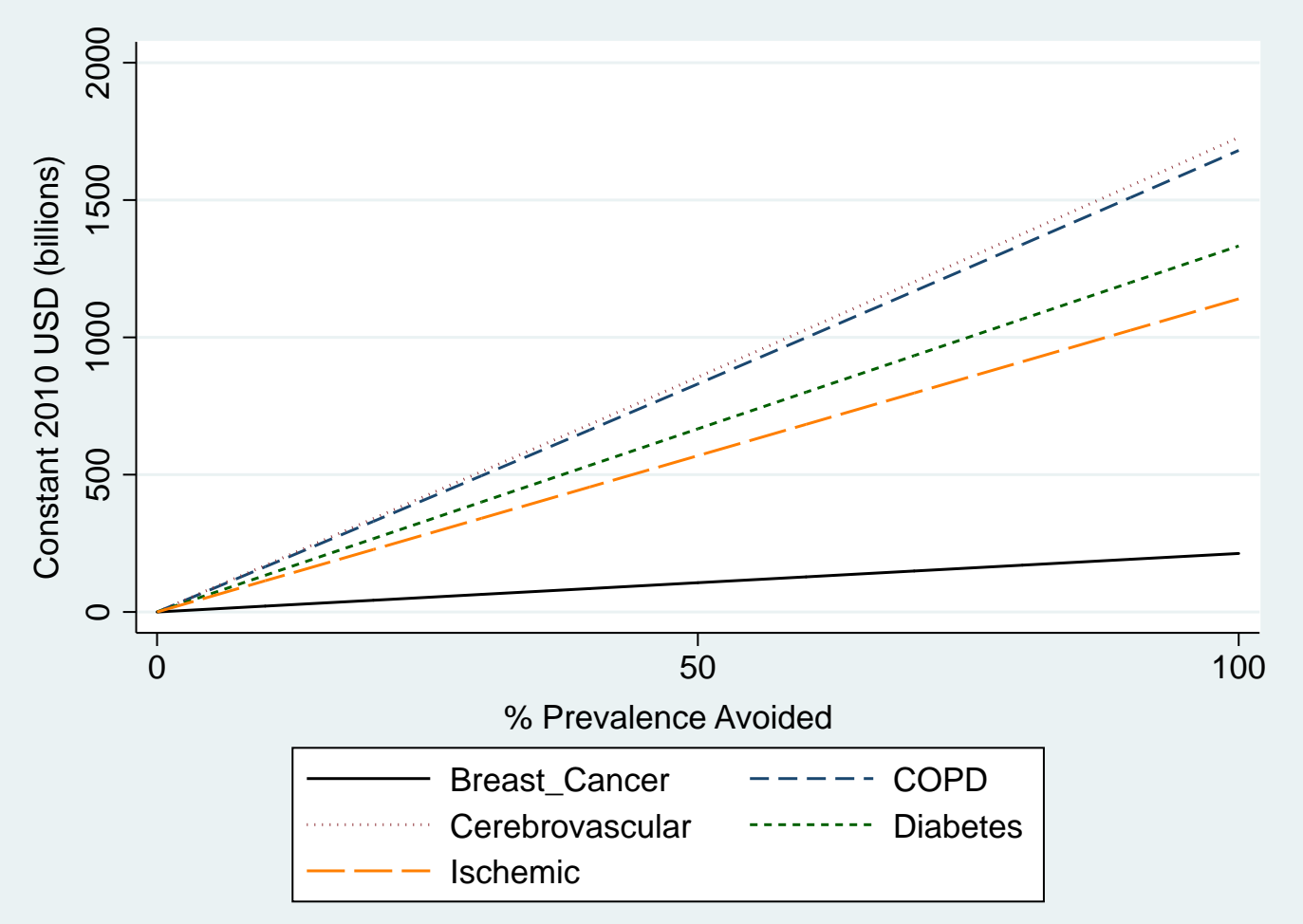

Figures 2-4 display, by disease, the estimated economic cost savings for a given percentage of prevalence averted. For example, the estimate at $10 \%$ compares the cumulative difference in GDP in that country between the status quo scenario with disease prevalence as predicted and the counterfactual scenario, where disease prevalence is reduced by $10 \%$. Results are shown in billions of real USD with a base year of 2010 and are cumulative over the period of interest (2010-2030). These estimates indicate that the most costly condition varies by country, although breast cancer is generally the least costly. For example, in China the most costly condition is cerebrovascular disease, and in Japan and South Korea it is diabetes. Interestingly, COPD is expected to cost China 1.7 trillion USD over the two decades. This is roughly $10.4 \%$ of China's total NCD loss, compared with only $3.1 \%$ in Japan and $5.1 \%$ in South Korea. The high prevalence of COPD in China is related to its air pollution and the large fraction of its population that smokes. Overall, the ranking of the impact of the other non-communicable diseases varies among the three countries.

We observe that the cost estimates increase roughly linearly with disease prevalence averted. This linearity is not surprising because (19) is a good approximation of the loss in labour supply given that the mortality related to each disease is small. Another feature apparent from these figures is that the burden of non-communicable diseases is much lower in South Korea than in the other two countries. 
Figure 3: Differential GDP Associated with Averted Disease Prevalence for Japan (in billions of 2010 USD)

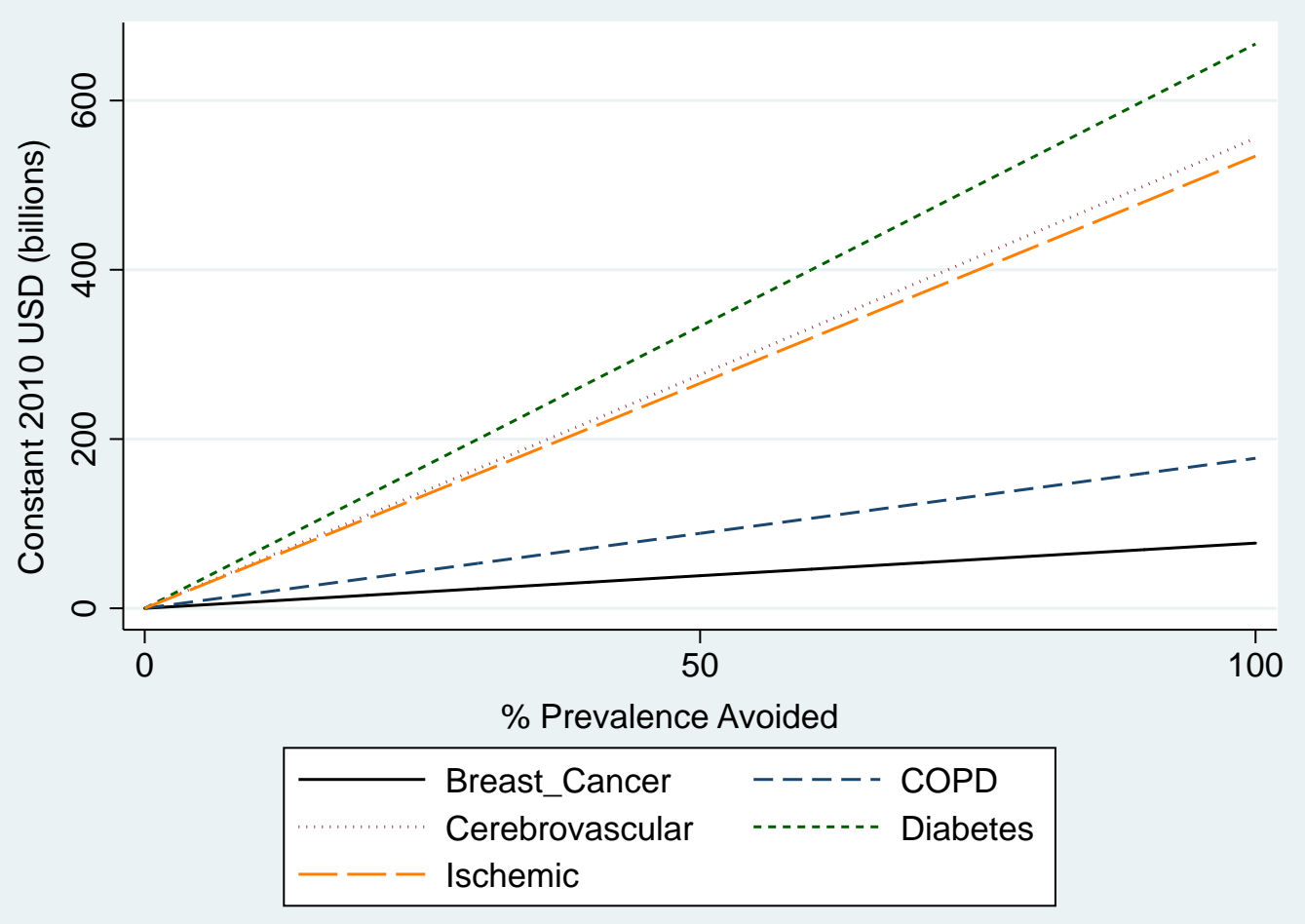

The final row of Table 2 shows the estimates of the total impact of non-communicable diseases in the five domains (cardiovascular diseases, cancer, chronic respiratory diseases, diabetes, and mental health conditions), after the estimates for the individual diseases have been scaled. Estimates are again given in real USD with a base year of 2010 for the period 2010-2030. The results indicate that the total economic costs of chronic conditions are 16 trillion USD in China, 5.7 trillion USD in Japan, and 1.5 trillion USD in South Korea.

Table 2: Estimates of Total Disease Burden 2010-2030 (100\% of Prevalence Averted) in 2010 USD (Billions)

\begin{tabular}{lccc}
\hline Disease & China & Japan & South Korea \\
\hline Ischemic Heart Disease & 1,140 & 534 & 119 \\
Cerebrovascular Disease & 1,728 & 555 & 145 \\
Diabetes & 1,333 & 667 & 280 \\
COPD & 1,681 & 177 & 77 \\
Breast Cancer & 213 & 77 & 12 \\
Total (Including Mental Health Conditions) & 16,190 & 5,707 & 1,511 \\
\hline
\end{tabular}

As previous estimates using the production function-based approach have not included the treatment cost mechanism, we investigate the contribution of this pathway to our estimates of the total disease burden. Table A3 in the Appendix shows model estimates in 
Figure 4: Differential GDP Associated with Averted Disease Prevalence for South Korea (in billions of 2010 USD)

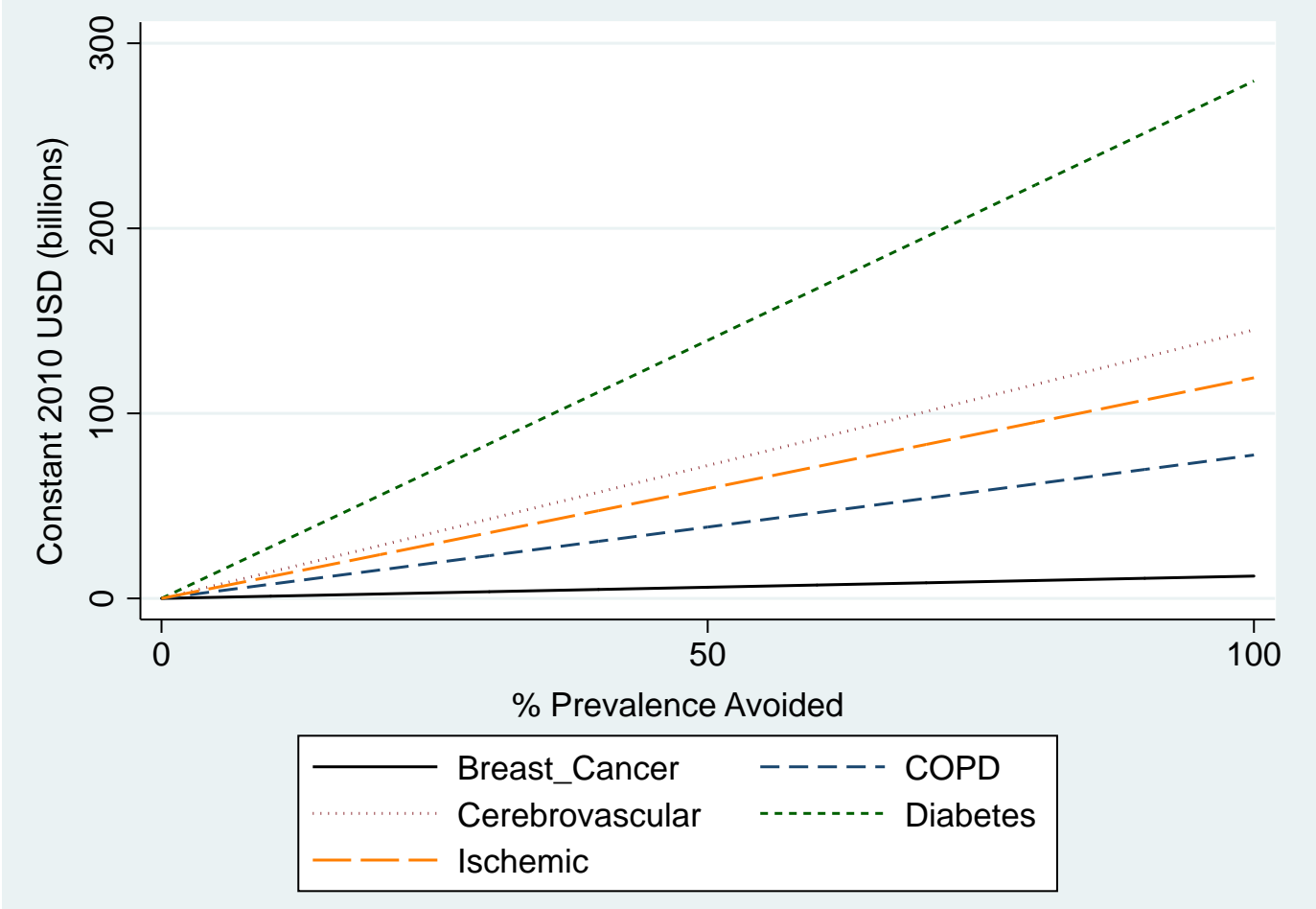

which we exclude treatment costs, and we use these results to establish the contribution of treatment costs to the overall total in Figure 5. For China, treatment costs account for $64 \%$ of the costs of NCDs, while the corresponding figure is $33 \%$ for Japan and $37 \%$ for South Korea. The relatively higher contribution of treatment costs in China can partly be explained by its large gross savings rate (around 50\% according to the World Bank), compared with that of Japan (22\%) and that of South Korea (35\%). In our model, $\chi$ in Equation (6) is approximated by the savings rate. A higher savings rate means that a larger proportion of resources used in treatment could otherwise be used as investment in physical capital. This leads to a larger output loss for countries with a higher savings rate.

Our calculations highlight the importance of incorporating the treatment cost mechanism as an additional pathway into the model for estimating the economic impact of chronic conditions. Differences in the relative contribution of this pathway are likely due to heterogeneity in the prevalence of different conditions and country-specific factors relating to health care systems.

One question that our analysis raises is whether considering the total costs associated with NCDs as measured by reducing their prevalence to zero is reasonable. To get an estimate of the total economic burden of certain conditions, this is indeed what we would 
like to know. However, when assessing the impact of realistic reductions in prevalence that health policies can achieve, considering a scenario in which a particular disease is eliminated is not reasonable. Chronic conditions may persist even under an ideal health care system, and even technological advances might not be sufficient to reduce prevalence to zero. Therefore, we also consider the costs associated with NCDs in a scenario where we calculate the reduction in mortality for each disease such that the corresponding case fatality rate reaches the minimum among OECD countries. For example, for China we estimate how much COPD mortality would have to be reduced to ensure that China had the same COPD-related case fatality rate (the proportion of reported cases of a specific disease that are fatal within a specified time frame) as the OECD country with the lowest COPD-related case fatality rate. The rationale for this analysis is that such a reduction is a realistic target because another country has already achieved it. More specifically, the lowest case fatality rates for ischemic heart disease, COPD, and cerebrovascular diseases are set to those in Slovenia, Estonia, and Slovakia, respectively. For breast cancer and diabetes the lowest levels are set to those in Cyprus and Iceland. ${ }^{9}$ The estimates are shown in Table 3 and, while lower than those presented in Table 2, indicate that reasonable targets for reductions in the prevalence of chronic conditions are likely to have substantial payoffs in terms of reducing the costs associated with NCDs.

Figure 5: \% Contribution of Treatment Costs to Total Estimate

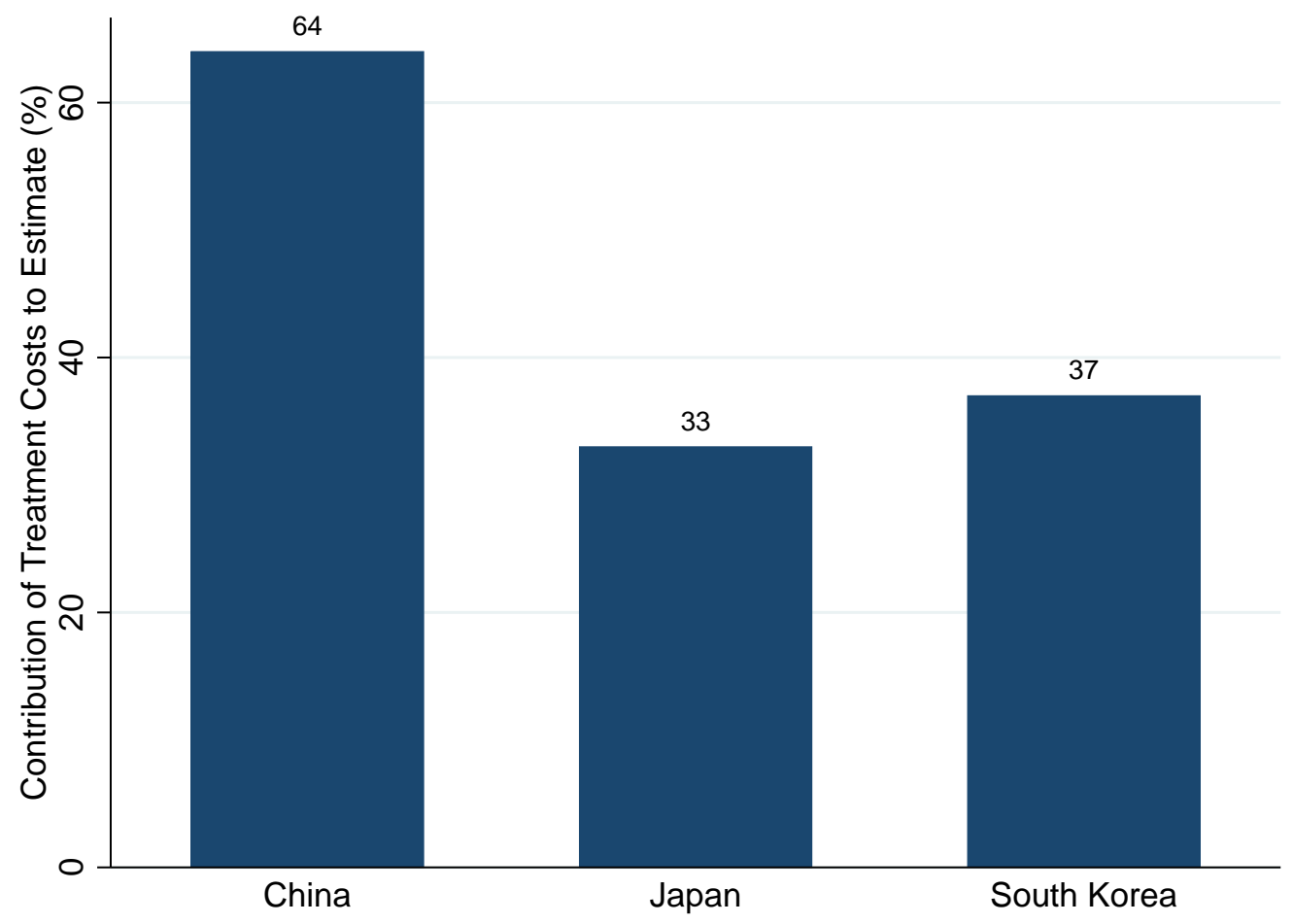

Finally, Table 4 provides the estimate of the total disease burden for different measures of

\footnotetext{
${ }^{9}$ Estimated case fatality rates were calculated by the authors based on 2015 disease incidence and mortality rates from Global Burden of Disease Study (2015).
} 
Table 3: Estimated Economic Burdens Assuming the Case Fatality Rates of the Countries with the Lowest Case Fatality Rates among OECD Countries

\begin{tabular}{|c|c|c|c|c|c|c|c|}
\hline Country & & $\begin{array}{c}\text { Ischemic } \\
\text { Heart Disease }\end{array}$ & $\begin{array}{c}\text { Cerebrovascular } \\
\text { Disease }\end{array}$ & Diabetes & COPD & $\begin{array}{l}\text { Breast } \\
\text { Cancer }\end{array}$ & Total Cost \\
\hline \multirow[t]{2}{*}{ China } & $\begin{array}{l}\text { Mortality Reduction (\%) } \\
\text { Under the Assumption }\end{array}$ & $29 \%$ & $18 \%$ & $29 \%$ & $59 \%$ & $44 \%$ & \multirow[t]{2}{*}{6,301} \\
\hline & $\begin{array}{l}\text { Burden of Excess Mortality } \\
\text { Billions (2010 USD) }\end{array}$ & 328 & 302 & 383 & 977 & 94 & \\
\hline \multirow[t]{2}{*}{ Japan } & $\begin{array}{l}\text { Mortality Reduction (\%) } \\
\text { Under the Assumption }\end{array}$ & $52 \%$ & $33 \%$ & $37 \%$ & $50 \%$ & $14 \%$ & \multirow[t]{2}{*}{1,667} \\
\hline & $\begin{array}{l}\text { Burden of Excess Mortality } \\
\text { Billions (2010 USD) }\end{array}$ & 274 & 181 & 249 & 88 & 11 & \\
\hline \multirow[t]{2}{*}{$\begin{array}{l}\text { South } \\
\text { Korea }\end{array}$} & $\begin{array}{l}\text { Mortality Reduction (\%) } \\
\text { Under the Assumption }\end{array}$ & $36 \%$ & $27 \%$ & $66 \%$ & $36 \%$ & $10 \%$ & \multirow[t]{2}{*}{502} \\
\hline & $\begin{array}{l}\text { Burden of Excess Mortality } \\
\text { Billions (2010 USD) }\end{array}$ & 42 & 39 & 184 & 28 & 1 & \\
\hline
\end{tabular}

economic performance. The total disease burden of NCDs (100\% reduction), if measured as a percentage of aggregate GDP in 2010, is largest in China with $265 \%$, followed by South Korea with 139\%, and Japan with 100\%. This measure, albeit straightforward, is biased in that it leads to a larger proportional burden for countries with a higher growth potential. Thus, the result is partly explained by the fact that China is expected to enjoy a much higher GDP growth rate than Japan and South Korea. The per capita figures ${ }^{10}$ show that Japan has the highest NCD burden with a per capita loss of $\$ 44,562$ (constant USD with the base year 2010), compared with only $\$ 12,099$ in China and $\$ 30,560$ in South Korea. Because Japan has the highest per capita GDP and health expenditure, the cost of each unit of mortality and morbidity is higher for the Japanese. The third measure in Table 4 shows that the NCD burdens of the three countries are actually relatively similar if adjusted for the income level (or GDP per capita) and for the growth potential. The NCD burden is equivalent to an annual tax of $7.17 \%$ on the economy in China, whereas the number is $4.46 \%$ for Japan and $5.24 \%$ for South Korea.

Table 4: Total Disease Burden for Different Measures of Economic Performance

\begin{tabular}{ccccc}
\hline & Country & \% of 2010 GDP & $\begin{array}{c}\text { Per Capita Loss } \\
\text { (2010 USD) }\end{array}$ & $\begin{array}{c}\text { \% of Total GDP } \\
\text { During 2010-2030 }\end{array}$ \\
\hline Estimates Associated with & China & $265 \%$ & 12,099 & $7.17 \%$ \\
$100 \%$ Reduction & Japan & $100 \%$ & 44,562 & $4.46 \%$ \\
of Disease Burden & South Korea & $139 \%$ & 30,560 & $5.24 \%$ \\
\hline Estimates Associated with & China & $103 \%$ & 4,709 & $2.79 \%$ \\
Lowest Case Fatality Rate & Japan & $29 \%$ & 13,016 & $1.30 \%$ \\
among OECD Countries & South Korea & $46 \%$ & 10,158 & $1.74 \%$ \\
\hline
\end{tabular}

While our model can be used to estimate the economic burden of non-communicable diseases and to assess the reduction in the burden from implementing a specific intervention, it is unrealistic to assume a certain percentage of mortality reduction is costless. By com-

\footnotetext{
${ }^{10}$ The per capita loss is calculated based on the population size as of 2010 .
} 
paring the total savings and total intervention costs, policymakers would be able to make better-informed decisions on which intervention is the most cost-beneficial. We adopted the intervention cost data for China from a recent study (Wang et al., 2014) and take ischemic heart disease as an example to compare different treatments and their costs for this disease.

Table 5 lists interventions that reduce the mortality rate of ischemic heart diseases. Strategy A1 uses four oral drugs (aspirin, beta-blockers, angiotensin-converting enzyme inhibitors, and statins) in patients with acute myocardial infarction (AMI). Strategy A2 uses clopidogrel in patients with AMI. Strategy B uses unfractionated heparin in patients with non-ST-segment-elevation myocardial infarction (NSTEMI). Strategy C1 uses primary percutaneous coronary intervention (PCI) in tertiary hospitals and thrombolysis with streptokinase in secondary hospitals in patients with ST-segment-elevation myocardial infarction (STEMI). Strategy C2 uses primary PCI in all patients with STEMI, and strategy C3 uses primary PCI in high-risk patients with NSTEMI in tertiary hospitals.

Table 5: Intervention Cost and Mortality Reduction for Different Interventions

\begin{tabular}{lcc}
\hline Intervention & Mortality Reduction & $\begin{array}{c}\text { Per Capita Intervention Cost } \\
(2010 \text { USD })\end{array}$ \\
\hline Strategy A1 & $1.3 \%$ & 0.040 \\
Strategy A2 & $0.4 \%$ & 0.073 \\
Strategy B & $0.3 \%$ & 0.007 \\
Strategy C1 & $4.9 \%$ & 0.436 \\
Strategy C2 & $7.2 \%$ & 0.762 \\
Strategy C3 & $0.4 \%$ & 0.097 \\
\hline
\end{tabular}

Table 6 shows the total savings and total intervention cost from 2010-2030 for each intervention in Table 5. Five of the six interventions are cost-beneficial. Specifically, strategy $\mathrm{B}$ has the highest benefit-cost ratio, followed by strategies $\mathrm{A} 1, \mathrm{C} 1, \mathrm{C} 2$, and A2. Implementing strategy $\mathrm{C} 3$ is not cost-beneficial.

Table 6: Estimates of Total Savings and Total Intervention Cost for Different Interventions in 2010 USD (Billions)

\begin{tabular}{lcccc}
\hline Intervention & Mortality reduction & Total Savings & Total Intervention Cost & Benefit-Cost Ratio \\
\hline Strategy A1 & $1.3 \%$ & 13.95 & 1.15 & 12.13 \\
Strategy A2 & $0.4 \%$ & 3.05 & 2.09 & 1.46 \\
Strategy B & $0.3 \%$ & 3.27 & 0.19 & 17.21 \\
Strategy C1 & $4.9 \%$ & 46.83 & 12.40 & 3.78 \\
Strategy C2 & $7.2 \%$ & 66.36 & 21.66 & 3.06 \\
Strategy C3 & $0.4 \%$ & 2.56 & 2.77 & 0.92 \\
\hline
\end{tabular}

In Table 7 we compare the incremental cost-effectiveness ratio (ICER) from (Wang et al., 2014) with the benefit-cost ratios that we calculated. The thresholds recommended by WHO-CHOICE were used to assess the degree of cost-effectiveness. An intervention is 
Table 7: Comparison between Cost-Benefit Analysis and Cost-Effectiveness Analysis

\begin{tabular}{lcc}
\hline Intervention & Benefit-Cost Ratio & ICER (Cost per QALY Gained) \\
\hline Strategy A1 & 12.13 & $\$ 3,100$ \\
Strategy A2 & 1.46 & $\$ 17,600$ \\
Strategy B & 17.21 & $\$ 2,800$ \\
Strategy C1 & 3.78 & $\$ 9,000$ \\
Strategy C2 & 3.05 & $\$ 10,700$ \\
Strategy C3 & 0.92 & $\$ 23,400$ \\
\hline
\end{tabular}

deemed highly cost-effective if ICER is less than the nation's GDP per capita, is deemed moderately cost-effective if ICER is between 1 and 3 times GDP per capita, and is deemed not cost-effective if ICER is larger than 3 times GDP per capita. The GDP per capita of China in 2013 (adjusted by inflation) was $\$ 5,721$ according to the World Bank.

From Table 7, we can conclude that the interventions rank the same for the cost benefit analysis and for the cost-effectiveness analysis, while the cutoff levels differ. Strategies $\mathrm{A} 1$ and $\mathrm{B}$ are highly cost-effective, $\mathrm{C} 1$ and $\mathrm{C} 2$ are moderately cost-effective, while A2 and C3 are not cost-effective. In our study, by contrast, all strategies except C3 are cost-beneficial. This is because our calculation is different from cost-effectiveness analysis. We not only take into account the health outcome, but also the economic impact. For example, the saved treatment cost from one intervention can be used to invest in physical capital accumulation. Overall, strategy B has the highest benefit-cost ratio, followed by strategy A1. This means that implementing strategies A1 and B would save much more money for China from 2010-2030 than they cost. While strategy A2 is less cost-beneficial than these two, the monetary value saved from this intervention is still higher than the total intervention cost. Finally, note that our results actually represent a lower bound of the benefits because the utility value that individuals assign to a longer and healthier life is not quantified and because general equilibrium repercussions and a feedback effect from income growth on health are not considered.

\section{Conclusions}

We implement a macroeconomic production function-based approach to assess the economic burden of non-communicable diseases. The advantage of this approach over alternatives is that we can account for economic adjustment mechanisms and spillover effects on labour markets and for heterogeneous human capital accumulation associated with increases in disease prevalence. Using a human capital augmented production function as proposed by Lucas (1988), we incorporate morbidity and mortality effects into the model and account for treatment costs. We apply our approach to calculate the economic impact of non-communicable diseases for China, Japan, and South Korea, three countries facing 
rapid population ageing. Our results indicate that chronic conditions are likely to be very costly in terms of lost output, with estimates of the total burden over the time period 2010-2030 on the order of 16, 5.7, and 1.5 trillion 2010 USD for China, Japan, and South Korea, respectively. Though the losses differ significantly at both aggregate and per capita levels, the NCD burdens of the three countries are actually quite similar after adjusting for the growth potential and the income level. In this case the figures are 7.17\%, 4.46\%, and $5.24 \%$ of total GDP for China, Japan, and South Korea, respectively, during 2010-2030. We also applied a cost-benefit analysis to a set of intervention strategies in China and showed that the total savings from all interventions are high and five of six strategies are cost-beneficial. This result implies that a broader range of interventions can be recommended to policymakers from an economic perspective than from a pure cost-effectiveness perspective.

Cross-country heterogeneity exists in the ranking of disease importance, which likely reflects differential exposure to risk factors, smoking patterns, and environmental pollution. A more detailed analysis of these differences is an important topic for future research. The main conclusion of the paper is that the economic burden associated with noncommunicable diseases in East Asia, as elsewhere, is substantial. Efforts to tackle the spread of chronic conditions and their associated risk factors now are likely to have substantial pay-offs in the future.

This model is flexible and could also be used to explore the impact of other factors impinging on health such as communicable diseases and road-traffic accidents. In addition, our approach is also relevant for modelling the impact of other health domains, such as communicable diseases. In this paper we have stayed within the production function-based framework, which has the advantages of i) providing a tractable and parsimonious method for analysing the economic burden of chronic conditions and ii) leading to a conservative estimate of the economic burden of diseases. This framework lays the ground for the development of a micro-founded computable general equilibrium model in future research.

\section{References}

D. Abegunde and A. Stanciole. An estimation of the economic impact of chronic noncommunicable diseases in selected countries. WHO Working Paper, Department of Chronic Diseases and Health Promotion, Geneva, 2006.

D. Acemoglu and S. Johnson. Disease and development: The effect of life expectancy on economic growth. Journal of Political Economy, 115(6):925-985, 2007.

D. Acemoglu and S. Johnson. Disease and development: a reply to Bloom, Canning, and Fink. The Journal of Political Economy, 122(6): 1367-1375, 2014. 
P. Aghion, P. Howitt, and F. Murtin. The relationship between health and growth: when Lucas meets Nelson-Phelps. Review of Economics and Institutions, 2(1):1-24, 2011.

R. J. Barro. Economic growth in a cross section of countries. Quarterly Journal of Economics, 106(2):407-443, 1991.

N. Beaulieu, D. E. Bloom, L. R. Bloom, and R. Stein. Breakaway: The global burden of cancer challenges and opportunities. The Economist Intelligence Unit, London: Livestrong, 2009.

D. E. Bloom, E. Cafiero, E. Jan-Llopis, S. Abrahams-Gessel, L. R. Bloom, S. Fathima, A. B. Feigl, T. Gaziano, A. Hamandi, and M. Mowafi. The global economic burden of noncommunicable diseases. Technical report, Program on the Global Demography of Aging, Geneva, Switzerland, 2012.

D. E. Bloom, E. T. Cafiero-Fonseca, M. E. McGovern, and K. Prettner. China and India's descent into chronic disease: Killing themselves slowly. Milken Institute Review, 2nd Quarter:24-33, 2014a.

D. E. Bloom, E. T. Cafiero-Fonseca, M. E. McGovern, K. Prettner, A. Stanciole, J. Weiss, S. Bakkila, and L. Rosenberg. The macroeconomic impact of non-communicable diseases in China and India: Estimates, projections, and comparisons. The Journal of the Economics of Ageing, 4:100-111, December 2014b.

D. E. Bloom, D. Canning, and G. Fink. Disease and development revisited. The Journal of Political Economy, 122(6):1355-1366, 2014c.

D. E. Bloom, D. Canning, R. K. Mansfield, and M. Moore. Demographic change, social security systems, and savings. Journal of Monetary Economics, 54(1):92-114, 2007.

D. E. Bloom, D. Canning, and M. Moore. Optimal retirement with increasing longevity. Scandinavian Journal of Economics, 116(3):838-858, 2014d.

D. E. Bloom, D. Canning, and J. Sevilla. The effect of health on economic growth: A production function approach. World Development, 32(1):1-13, 2004.

D. E. Bloom, S. Chen, M. E. McGovern, K. Prettner, V. Candeias, A. Bernaert, and S. Cristin. Economics of non-communicable diseases in Indonesia. Technical report, World Economic Forum, Indonesia, Jakarta, 2015.

D. E. Bloom, D. Chisholm, E. Jan-Llopis, K. Prettner, A. Stein, and A. Feigl. From burden to "best buys": Reducing the economic impact of non-communicable disease in low-and middle-income countries. Technical report, WHO executive summary, Geneva, Switzerland, 2011.

H.-S. Chang, H.-J. Kim, C.-M. Nam, S.-J. Lim, Y.-H. Jang, S. Kim, and H.-Y. Kang. The socioeconomic burden of coronary heart disease in Korea. Journal of Preventive Medicine and Public Health, 45(5):291-300, 2012.

M. Cervellati and U. Sunde. Life expectancy and economic growth: the role of the demographic transition. Journal of Economic Growth, 16(2):99-133, 2011.

G. Currie, K. D. Kerfoot, C. Donaldson, and C. Macarthur. Are cost of injury studies useful? Injury Prevention, 6(3):175-176, 2000. 
D. Cutler, A. Deaton, and A. Lleras-Muney. The determinants of mortality. Journal of Economic Perspectives, 20(3):1, 2006.

S. N. Durlauf, P. A. Johnson, and J. R. Temple. Growth econometrics. In Handbook of Economic Growth, volume 1, pages 555-677. North Holland, Amsterdam, Netherlands, 2005.

D. S. Dwyer and O. S. Mitchell. Health problems as determinants of retirement: Are self-rated measures endogenous? Journal of Health Economics, 18(2):173-193, 1999.

M. Eberhardt and F. Teal. Econometrics for grumblers: A new look at the literature on cross country growth empirics. Journal of Economic Surveys, 25(1):109-155, 2011.

I. Frankovic, M. Kuhn, and S. Wrzaczek. Medical care within an OLG economy with realistic demography. No. 02/2016. ECON WPS-Vienna University of Technology Working Papers in Economic Theory and Policy, 2016

Global Burden of Disease Study 2015. Global burden of disease study 2015 (GBD 2015) results. Seattle, United States: Institute for Health Metrics and Evaluation (IHME), 2016.

V. Grossmann, T. Steger, and T. Trimborn. Dynamically optimal R\&D subsidization. Journal of Economic Dynamics and Control, 37(3):516-534, 2013.

R. E. Hall and C. I. Jones. Why do some countries produce so much more output per worker than others? Quarterly Journal of Economics, 114(1):83-116, 1999.

J. J. Heckman, L. J. Lochner, and P. E. Todd. Earnings functions, rates of return and treatment effects: The Mincer equation and beyond. In Handbook of the Economics of Education, volume 1, pages 307-458. North Holland, Amsterdam, Netherlands, 2006.

International Diabetes Federation. IDF diabetes atlas - 7th edition, 2015. URL: http://www.diabetesatlas.org

Institute for Health Metrics and Evaluation. India global burden of disease study 2010 (GBD 2010) results 1990-2010. Technical report, Institute for Health Metrics and Evaluation, Seattle, 2013.

N. Islam. Growth empirics: A panel data approach. Quarterly Journal of Economics, 110 (4):1127-1170, 1995.

R. Jäckle and O. Himmler. Health and wages: Panel data estimates considering selection and endogeneity. Journal of Human Resources, 45(2):364-406, 2010.

A. M. Jones, N. Rice, and J. Roberts. Sick of work or too sick to work? Evidence on self-reported health shocks and early retirement from the BHPS. Economic Modelling, 27(4):866-880, 2010.

C. I. Jones. R\&D-based models of economic growth. Journal of Political Economy, 103 (4):759-784, 1995.

P. M. Kearney, M. Whelton, K. Reynolds, P. Muntner, P. K. Whelton, and J. He. Global burden of hypertension: Analysis of worldwide data. The Lancet, 365(9455):217-223, 2005. ISSN 0140-6736. 
S.-G. Kim, M.-I. Hahm, K.-S. Choi, N.-Y. Seung, H.-R. Shin, and E.-C. Park. The economic burden of cancer in Korea in 2002. European Journal of Cancer Care, 17(2): 136-144, 2008.

M. Kuhn and K. Prettner. Growth and welfare effects of health care in knowledge-based economies. Journal of Health Economics, 46(A):100-119, 2016.

M. Kuhn, S. Wrzaczek, G. Feichtinger, and A. Prskawetz. Optimal choice of health and retirement in a life-cycle model. Journal of Economic Theory, 158(A):186-212, 2015.

D. N. Lakdawalla, E. C. Sun, A. B. Jena, C. M. Reyes, D. P. Goldman, and T. J. Philipson. An economic evaluation of the war on cancer. Journal of Health Economics, 29(3):333$346,2010$.

S. Lim, H. Kim, C. Nam, H. Chang, Y.-H. Jang, S. Kim, and H.-Y. Kang. Socioeconomic costs of stroke in Korea: Estimated from the Korea national health insurance claims database. J Prev Med Public Health, 42(4):251-260, 2009.

M. Lindeboom and M. Kerkhofs. Health and work of the elderly: Subjective health measures, reporting errors and endogeneity in the relationship between health and work. Journal of Applied Econometrics, 24(6):1024-1046, 2009.

G. López-Casasnovas, B. Rivera, and L. Currais. Health and economic growth: Findings and policy implications. MIT Press, Cambridge, 2005.

R. Lozano, H. Wang, K. J. Foreman, J. K. Rajaratnam, M. Naghavi, J. R. Marcus, L. Dwyer-Lindgren, K. T. Lofgren, D. Phillips, and C. Atkinson. Progress towards millennium development goals 4 and 5 on maternal and child mortality: An updated systematic analysis. The Lancet, 378(9797):1139-1165, 2011.

R. E. Lucas. On the mechanics of economic development. Journal of Monetary Economics, $22(1): 3-42,1988$.

K. McGarry. Health and retirement: Do changes in health affect retirement expectations? Journal of Human Resources, 39(3):624-648, 2004.

J. A. Mincer. Schooling and earnings. In Schooling, Experience, and Earnings, pages 41-63. NBER, New York, 1974.

K. M. Murphy and R. H. Topel. The value of health and longevity. Journal of Political Economy, 114(5):871-904, 2006.

C. J. Murray, T. Vos, R. Lozano, M. Naghavi, A. D. Flaxman, C. Michaud, M. Ezzati, K. Shibuya, J. A. Salomon, and S. Abdalla. Disability-adjusted life years (DALYs) for 291 diseases and injuries in 21 regions, 1990-2010: A systematic analysis for the global burden of disease study 2010. The Lancet, 380(9859):2197-2223, 2013.

S. Nishimura and C. Zaher. Cost impact of COPD in Japan: Opportunities and challenges? Respirology, 9(4):466-473, 2004.

K. Prettner and D. Canning. Increasing life expectancy and optimal retirement in general equilibrium. Economic Theory, 56(1):191-217, 2014.

L. Pritchett and L. H. Summers. Wealthier is healthier. Journal of Human Resources, 34 (1):841-868, 1996. 
G. Psacharopoulos. Returns to investment in education: A global update. World Development, 22(9):1325-1343, 1994.

D. P. Rice. Cost of illness studies: What is good about them? Injury Prevention, 6(3): 177-179, 2000

X. Sala-i Martin. I just ran two million regressions. American Economic Review, 87(2): 178-183, 1997.

X. Sala-i Martin, G. Doppelhofer, and R. I. Miller. Determinants of long-term growth: A Bayesian averaging of classical estimates (BACE) approach. American Economic Review, 94(4):813, 2004.

R. M. Solow. A contribution to the theory of economic growth. Quarterly Journal of Economics, 70(1):65-94, 1956.

M. Suhrcke and D. Urban. Are cardiovascular diseases bad for economic growth? Health Economics, 19(12):1478-1496, 2010.

W. K. Viscusi and J. E. Aldy. The value of a statistical life: A critical review of market estimates throughout the world. Journal of Risk and Uncertainty, 27(1):5-76, 2003.

M. Wang, A. E. Moran, J. Liu, P. G. Coxson, P. A. Heidenreich, D. Gu, J. He, L. Goldman and D. Zhao. Cost-effectiveness of optimal use of acute myocardial infarction treatments and impact on coronary heart disease mortality in China. Circulation: Cardiovascular Quality and Outcomes, 7(1):78-85, 2014.

D. N. Weil. Accounting for the effect of health on economic growth. Quarterly Journal of Economics, 122(3):1265-1306, 2007.

D. N. Weil. Health and economic growth. In The Handbook of Economic Growth, volume 2. North Holland, Amsterdam, Netherlands, 2014.

World Bank. World development indicators, 2015. http://data.worldbank.org/ indicatorID-57.

World Bank. Global economic prospects, January 2017 weak investment in uncertain times. Washington, DC: World Bank, 2017.

World Health Organization. WHO guide to identifying the economic consequences of disease and injury. Geneva: World Health Organization, 2009 


\section{Appendix: Additional results}

Table A1: Data Sources of Treatment Costs

\begin{tabular}{cc}
\hline Disease & Treatment Cost Source \\
\hline Ischemic Heart Disease & Chang et al. (2012) \\
Cerebrovascular Disease & Lim et al. (2009) \\
Diabetes & International Diabetes Federation (2015) \\
COPD & Nishimura and Zaher (2004) \\
Breast Cancer & Kim et al. (2008) \\
\hline
\end{tabular}

Table A2: Estimates of Treatment Cost per Country (2010 USD)

\begin{tabular}{lcc}
\hline Country & Disease & Treatment Cost per Capita (in 2010 USD) \\
\hline China & Ischemic Heart Disease & $\$ 13.29$ \\
Japan & Ischemic Heart Disease & $\$ 69.39$ \\
Korea & Ischemic Heart Disease & $\$ 29.23$ \\
China & Cerebrovascular Disease & $\$ 12.97$ \\
Japan & Cerebrovascular Disease & $\$ 67.76$ \\
Korea & Cerebrovascular Disease & $\$ 28.54$ \\
China & Diabetes & $\$ 11.62$ \\
Japan & Diabetes & $\$ 242.96$ \\
Korea & Diabetes & $\$ 154.45$ \\
China & COPD & $\$ 13.32$ \\
Japan & COPD & $\$ 69.94$ \\
Korea & COPD & $\$ 26.74$ \\
China & Breast Cancer & $\$ 2.78$ \\
Japan & Breast Cancer & $\$ 15.68$ \\
Korea & Breast Cancer & $\$ 4.91$ \\
\hline
\end{tabular}

Table A3: Estimates Excluding Treatment Costs in 2010 USD (Billions)

\begin{tabular}{lccc}
\hline Disease & China & Japan & Korea \\
\hline Ischemic Heart Disease & 388 & 428 & 90 \\
Cerebrovascular Disease & 993 & 452 & 117 \\
Diabetes & 268 & 243 & 128 \\
COPD & 926 & 74 & 51 \\
Breast Cancer & 55 & 53 & 7 \\
Total (Including Mental Health Conditions) & 5,781 & 3,775 & 943 \\
\hline
\end{tabular}

